\title{
Use of Social Networks as an Education Tool
}

\author{
Filiz Tiryakioglu \\ Funda Erzurum \\ Anadolu University, Turkey
}

\begin{abstract}
Social network, particularly Facebook, can be defined as a unique online service, platform, or area where social communication and/or social relations can be established and individuals intensely share information. This definition implies that communication specialists should have more expertise and interest in social media than any other group of experts. Based on this assumption, the present study investigated the views and attitudes of instructors in the Faculty of Communication Sciences at Anadolu University in Turkey, which is a country where the total number of Facebook users ranks fourth in the world. The sample of the study consisted of 67 professors with various levels of academic titles. Data were gathered through a specially-designed survey form including 52 items in four subcategories. Results suggest that three fourth of instructors have a Facebook account and they spend less than half an hour per day on Facebook. There is no genderrelated difference among the faculty in terms of attitudes toward Facebook. Instructors who are younger than 45 years old login Facebook on daily basis, while senior faculty login several times a week. Two in every three instructors use Facebook mainly as a tool of communication with friends. Finally, two thirds of the faculty think that Facebook can provide important contributions to social interactions among students as well as to communications between instructors and students.
\end{abstract}

Key Words: Facebook; Social networks; Communication technologies; Educational tools

\section{Introduction}

Starting with emergence of the Internet as a public sphere, many unprecedented changes have occurred in communication types and formats in daily life. Face-to-face communication in interpersonal relationships has been gradually replaced with communications via technological devices. This change has also been associated with new types of relationships (Murray, 2008, p.8). Social networks within the scope of social media are almost at the heart of these virtual communication forms.

Social networks are platforms for virtual social lives created by people over the Internet. Individuals define themselves in such networks so that they communicate with other people sharing same or different cultural backgrounds/dimensions through powerful communication opportunities provided by the Internet.

The first known network in this area is considered the SixDegrees which was constructed in 1997. Particularly after 2003, rapid and important developments were experienced in social networks; consequently the number of users has increased quickly. The worldwide growth of 
social communication networks gained incredible pace and popularity. Among these networks, the most common one is known as Facebook (Toprak et al., 2009, p.27).

As of February 2011, Facebook has more than 500 millions of users around the world. Fifty percent of total users actively login the site every day. Users spend a total of 700 billion minutes per month on Facebook. More than 200 million users have mobile connection to Facebook. There are about a billion of locations (pages, groups, activities etc.) in Facebook where users interact with each other. An ordinary user is connected to 80 groups, activities or society pages and shares an average of 90 contents per month. More than 30 billions of contents per month are shared by users (http://www.facebook.com).

When over 500 millions of people worldwide started to spend a substantial part of their daily lives in Facebook, this social network also attracted interest of sociologists and psychologists. According to researchers, social networks improve communication skills, enhance participation as well as social commitment, reinforce peer support, and ensure realization of education based on collaboration strategies. Furthermore, social networking sites can be easily and inexpensively used without substantial support from universities. That is also to say that they can be successfully integrated into educational processes. In appears that this type of use rapidly becomes widespread all around the world (Gulbahar et al., 2010, p.2).

It is a fact that Facebook is the largest social network with the biggest audience compared to similar media, particularly because it enables people communicate with their friends and exchange multimedia-based information conveniently. Hundreds of people, unaware of each others, may gather around a particular purpose via this social network and they may even decide to act together. Many individuals increasingly spend more time on this new medium. Despite it is generally accepted and as a social network, Facebook could also gain a unique position as a learning technology for educational purposes.

With a population of 26.198.200 Facebook users, Turkey ranks fourth in the world, following the United States, Indonesia, and the United Kingdom. Also, 34\% of the country's general population and $75 \%$ of the population with Internet access login the Facebook. Approximately $36 \%$ of the Turkish users are women and $64 \%$ are men. As far as age groups are concerned, $67 \%$ are between 18 and 34 years, $20 \%$ are younger than 18 years, and the remaining $15 \%$ are above 34 years (http://www.socialbakers.com). These figures imply that Facebook has a great potential for education of relatively young population of Turkey.

An interesting example in this area was presented by Heather Rogers of the Haversack Towson University. She used the Facebook Group titled "Female of 324 Reading Methods Group" for meeting teacher candidates in a reading class. The group functioned as a platform where class works were discussed, questions were asked, opinions were criticized, information was sent, and views were supported. The researcher recommended the construction of book clubs for supporting students read, performing book discussion, and using social networks for sharing readings. She also mentioned that these social networks might be used in courses like history and literature, preparing cultural guides and programming applications (Gulbahar et al., 2010, p.3). 


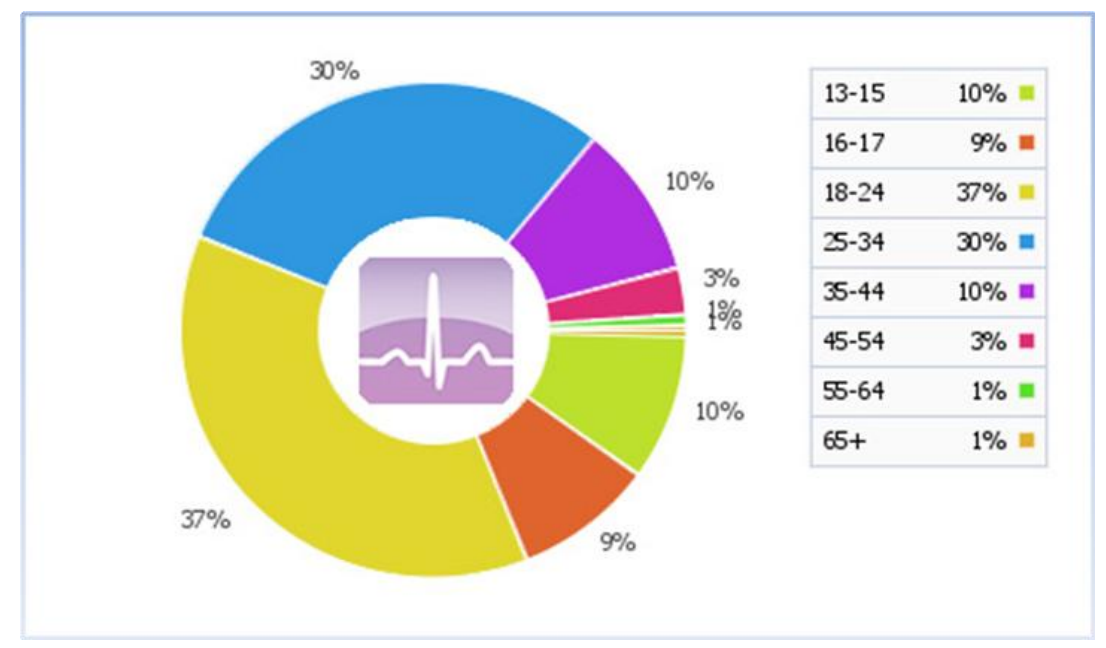

Figure 1. Use of Facebook in Turkey by Age Groups (http://www.socialbakers.com).

\section{Methods}

This study investigated the views and attitudes of academics regarding the use of Facebook for educational purposes. The study was conducted to test the hypothesis stating that "Although instructors who are older than 45 years old use Facebook in daily communication, they do not believe in the use of Facebook for educational purposes."

The data were gathered through a survey (a mixture of a questionnaire and a Likert-type scale) from instructors of the Faculty of Communication Sciences at Anadolu University in Turkey. As known, communication faculties are academic institutions providing educational opportunities to train qualified personnel for various areas of specialization in the media sector. Thus, it is expected that instructors of communication faculties should have more expertise and interest in social media including social networks.

There were a total of 75 instructors in four departments of the Faculty of Communication Sciences at Anadolu University including lecturers, assistant professors, associate professors, and full professors. The questionnaires were distributed to all 75 instructors but 67 of them were returned. Graduate assistants were not included in the study. The reason for this choice was that they are not authorized to teach classes independently or without supervision of a professor. Analysis of data was performed by using SPSS version 16.0.

The survey form included a total 52 items in 4 categories in order to collect information about demographics of the participants, adoption level of Facebook, purpose for using Facebook, and views on educational uses of Facebook. The survey form was reviewed and approved after some revisions by a panel of experts working on communication technologies. The validation of the survey was checked through a pilot test implemented in the same faculty before the actual implementation.

Items in the first category of the survey aimed to determine personal information about the participants. Age, gender, title, experience etc. were asked. Items in the second category, asked to what degree they adopted Facebook. Items in the third category asked for what purposes the participants used Facebook in daily life (finding friends, having good time, 
obtaining information, communicating with other people etc.). Items in the fourth category aimed to find out the views and attitudes of the participants regarding the use of Facebook for educational purposes.

Due to the nature of the study, descriptive statistical techniques were used in analyzing and reporting data. The findings were presented in relevant tables or figures and corresponding interpretations followed right after them.

\section{Theoretical Framework}

\section{Social Media versus Conventional Media}

Social media is a common concept which gained its position and popularity in our life as a recent consequence of Web 2.0. It refers to the locations with highly accessible and sharable content. It has become more widespread through social interaction using Internet and Web based technologies. In other words, the concept of social media refers to platforms such as social networks, blogs, micro-blogs, and forums where self-generated contents of users are shared by the user like a publisher. The possibility to make shared content reach more people may be increased when they are shared with popular individuals or if the shared content gains good interest. People share any and all types of personal experiences ranging from life stories to usefulness of a product or service purchased through social media such as Facebook, Friendfeed, Myspace, Twitter, and Youtube.

Having a position in the "conventional media" such as radio, television, newspaper etc. is associated with many challenges such as high costs and limitations pertaining to access to archived information. On the other hand, ability to be in "social media" mostly requires only Internet access. In short, specialization is not a prerequisite for content generation in social media (http://eticaret.garanti.com.tr).

Social media differs from conventional media. In general, particular resources are required for publishing information in conventional media; while social media is relatively without cost, and access devices are open to everybody. User is defined as a consumer-producer. It has active position as defined in the uses and gratifications approach. It both generates and consumes the content. It also has the ability to perform this in an interactive manner. The common characteristic of social media and conventional media is the ability to reach small or large audience. The content may reach nobody or to millions of people. Features providing support in determining differences between social media and conventional media may vary depending on the method used. Those features may be listed as follows:

- Access - Both conventional media and social media technologies enable everybody reach a particular audience.

- Accessibility - Production for conventional media is generally possessed by private companies and governments; social media tools can be, in general, used by everybody with a low cost or no cost. 
- Availability - Production of conventional media usually requires specialized skills and training. This is not valid for most productions of social media or in some cases, skills are completely different and everybody may complete production.

- Novelty - The time difference in conventional media communications (days, weeks, and even months) can be longer in comparison with the social media enabling instant effect and reaction. The time difference of reaction is decided by participants.

- Permanence - Conventional media cannot be changed after it is produced and published, whereas social media can be immediately changed via comments and repurposing.

- Following introduction of social media into our life, many issues in human life started to change; since content is produced by the user, creativity gained importance and participation took center stage. The strict differentiation between producer and audience of the content in conventional media is gone (http://www.asiamedia.ucla. edu/article).

\section{Social Networks}

In general, social network can be defined as an online service, platform, or area where social communication and relations can be established, and also individuals share information. Social networks offer the user ability to share online their views, feelings, activities, events, and fields of interest.

Today, many social network sites emerged, which reshaped communication, interaction, collaboration, and efforts of people. Degree of participation to social networks also constantly increases. Individuals may define themselves over Internet in the social life and they become a member of social networks in order to reach and communicate with friends of similar cultural level, field of interest, common background, and mutual friends. Thus, a group of friends can be enlarged and information exchange is enabled (Jordan, 1999, p.191).

People login social networks for different purposes. This condition leads to the fact that private lives are known by and shared with hundreds or even thousands of people who do not know each other. Social network sites have become an extremely important tool for sharing communication and obtaining new information as well as making new friendships. Moreover, social network environments offer possibilities for personal statements, creating interest groups, ensuring cooperation, and sharing information. Using several mouse clicks, people may send each other videos, images, or any other content (Aydogan \& Akyuz, 2010, p.66).

According to Perlman and Miller (2008), social sharing networks, which make people share all details of their lives with whole world, remove the sense of shame. However, it is also at the heart of many scientific claims ranging from health problems, loss of future job opportunities to conversion of users into "monster" due to deepening of jealousy and narcissism. After all, social sharing networks became an inevitable part of human life.

According to researchers, social networks improve communication skills, enhance participation and social commitment, reinforce peer support, and ensure realization of education based on 
collaboration. Moreover, social networking sites can be easily and inexpensively used without a substantial support from universities so that they can be integrated into educational process of students. Thus, following graduation from the university, students will have possibilities to re-access learning process over the Web and continue his/her studies (Gulbahar, Kalelioglu, \& Madran, 2010).

\section{Social Networks in Educational Environments}

Social network sites offer several possibilities such as socialization of individuals, ability to communicate with people living worldwide, ability to be a member of group which cannot be possible in real life due to geographical and physical constraints, self-expression and ability to receive information and share it. Problems pertaining to confidentiality, misuse of information and social network dependence are also undeniable facts. However, it is possible to make social networks advantageous through positive uses.

Social networks can also be successfully used in the field of education. Seguin and Seguin $(1995$, p.30) recommends educators that they may gain benefits such as program exchanges, job announcements, creating relief funds or searching such funds, arranging concurrent or non-concurrent conferences, and publishing studies conducted by themselves or their students. Moreover, studies such as course plans, activities etc. can be more efficiently used by a larger number of educators over a database.

When we examine advantages deriving from the use of social networks as an educational tool, interactivity and participation provided by such environments should be also mentioned. Advantages possibly deriving from use of social networks as an education tool can be listed as follows (Balci, 2010, p.466).

- Independence from time and location

- Improvement in quality, success, and efficiency of education by use of computer for education

- Ability to learn in more systematic manner and in shorter time due to advances in computer technology

- Individualization of learning

- Ability to have instant feedback

- Offering the student ability to repeat course content as much as desired

- Ease of displaying the content

- Allowing to the design of visual and auditory learning environments

- Ability to present courses that require laboratory applications to students via simulation, animation, and virtual laboratories

- Archiving course content and synchronized class (virtual class) applications

- Bidirectional communication

- Tendency towards more voluntary behaviors on the side of students for improving research, knowledge, and skills in comparison to conventional programs 
- Offering possibility to evaluate performance of students

- Minimizing risk of error in measuring evaluation results

- Improving skills of students and teachers to reach, evaluate, use, and efficiently cite the knowledge.

\section{Facebook}

Facebook is a social network which aims to enable people communicate with friends and exchange information. Being developed by Mark Zuckerberg, a student at Harvard University, in 4 February 2004, Facebook is primarily constructed for enabling communication between Harvard students. Later, it covered schools located around Boston and it started to accept membership of all students and graduates from all schools in the United States of America within one year. While individuals may become member using only e-mail address of the relevant school high schools and some large companies were added to the network and Facebook was opened to all e-mail addresses with some age constraints in 11 September 2006 (http://www.Facebook.com).

Facebook is an online social network software which enables users connect to each other via private or public correspondences based on different authorization levels in networks and join other groups and share contents with other users. Similar to other online social network sites (i.e. Friendster, MySpace), users define themselves via online profile, gain friendships, and write comments or information to profiles of others or the social content.

Since social communication networks are highly new, studies on their uses in education are very scarce. Based on several studies, a substantial proportion of students spend nonnegligible time in such social networks (Jones, Blackey, Fitzgibbon, \& Chew, 2010, p.776). This trend shows that educational environments constructed in social networks will better attract attention of students. When this is done successfully, it is often stated that educational experiences will be more effective.

\section{Findings}

\section{Personal Details}

A total of 75 instructors work in the Faculty of Communication Sciences at Anadolu University. Since three instructors (one professor and two associate professors) were commissioned to work in other universities, they could not participate in the study. Therefore, survey form could be delivered to 72 instructors. Of them, 18 were full professors, 15 were associate professors, 26 were assistant professors, and 13 were lecturers. Responses could be obtained from 67 faculty members and 5 instructors did not return the completed survey.

Of the faculty members participating in the study, 30 were female and 37 were male. This is consistent with the overall gender distribution.

The age group of 41-45 years had more participants (24 persons-36\%) than any other group. This indicates that most of instructors lecturing in the faculty are in middle ages. Of the remaining participants, $18(27 \%)$ were in the age group of $30-40$ years, $11(16 \%)$ were in the 
age group of $46-50$ years, $6(9 \%)$ were in the age group of $51-55$ years, and $8(12 \%)$ were above 56 years old.

\section{Use of Facebook}

Fifty of 67 instructors (75\%) responding the survey have a Facebook account. Of 50 instructors with an account, 25 are female and 25 are male. It is observed that Facebook users are heavily felt in the age range of $41-45$ years.

\begin{tabular}{|llll|}
$\begin{array}{l}\text { The instructors who } \\
\text { have a Facebook } \\
\text { account }\end{array}$ & $\begin{array}{l}\text { The instructors who } \\
\text { think positively about } \\
\text { Facebook }\end{array}$ & $\begin{array}{l}\text { The instructors who } \\
\text { use Facebook every } \\
\text { day }\end{array}$ & $\begin{array}{l}\text { The instructors who } \\
\text { spend half an hour or } \\
\text { less on Facebook }\end{array}$ \\
\hline $50(74 \%)$ & $33(66 \%)$ & $28(56 \%)$ & $37(74 \%)$ \\
\hline
\end{tabular}

Figure 2. Behaviors of Participants Concerning Use of Facebook

Twenty-eight of participants (56\%) stated that they check their Facebook account daily; 14 (28\%) stated that they login Facebook account several times a week; 6 (12\%) stated several times a month; and finally 2 participants (4\%) said that they check their Facebook accounts several times a year.

No significant difference between gender and frequency of use could be found. When we examined the relationship between age of participants and frequency of use, it was found that the participants aged under 45 years had daily logins to the Facebook. When the time spent is examined, it is observed that 37 of participants $(74 \%)$ spend half an hour or less per day. Of participants, only 1 participant stated more than 3 hours time spent in Facebook.

Considering the responses to questions about group membership, which is an indicator of being active in Facebook, it is found that 34 participants (68\%) had group membership. No significant difference is present with regard to the age and group membership. However, it is observed that tendency of male participants towards group membership is higher than female participants. When membership to groups pertaining to Internet and technology is particularly examined, it is revealed out that no female participant is a member of such groups. When distribution of group memberships is probed further, it was found that 30 participants were members to student groups, 40 were members to common interest groups, 5 were members to Internet and technology groups and 18 were members to organization and corporation groups. It is noted that one participant had a membership to more than one group and all participants who were members to Internet and technology groups were male. When relationship between age and group membership is examined, it is observed that participants who were members to a group were younger than 45 years old (79\%). Users who were older than 55 years have no group membership at all.

\section{Adoption of Facebook}

Responses given to questions for determining adoption of Facebook indicates that instructors adopted Facebook and they regularly use it. Thirty-seven participants (74\%) agreed that they benefited from the possibility of communicating with more than one participant. Twenty-eight 
participants (56\%) stated that they could share more things within shorter time. Number of participants who agreed that views and information shared in Facebook contributes to the personal development by offering different perspectives was 19 (38\%), 14 participants (28\%) were neutral to this question and $16(32 \%)$ did not agree.

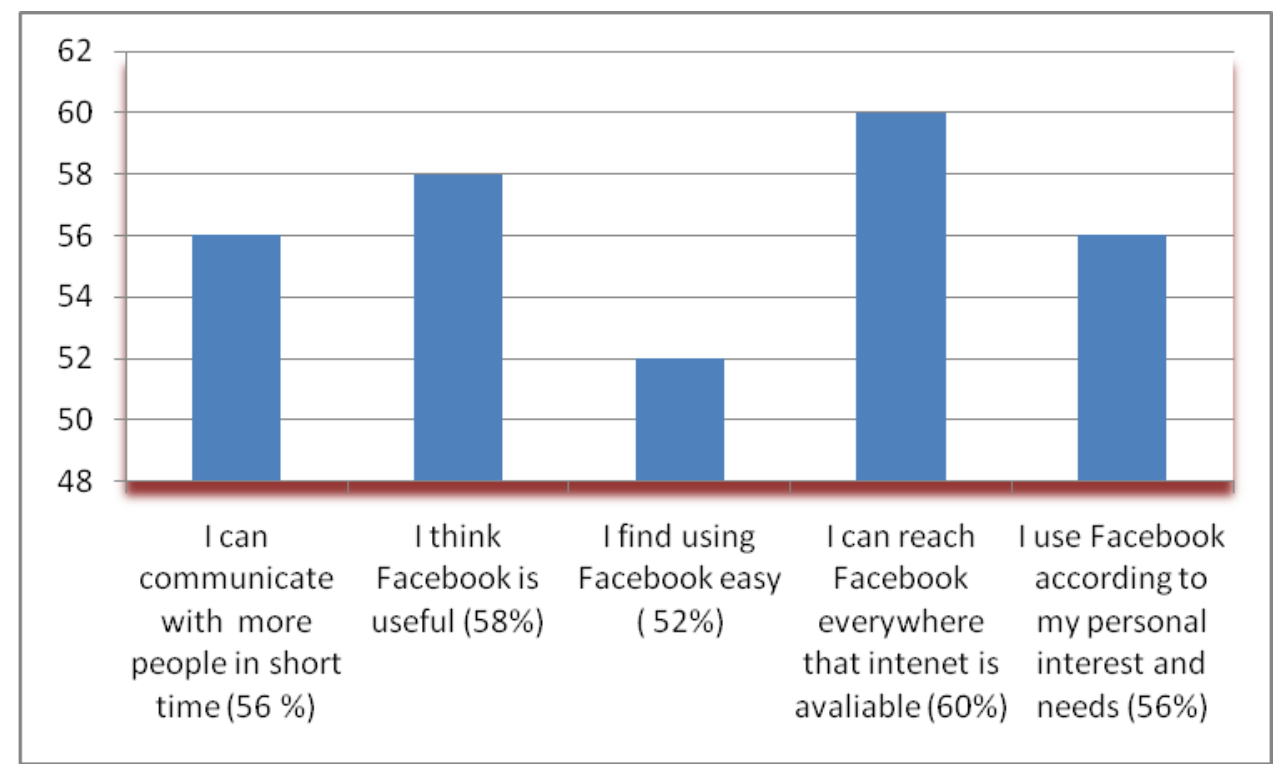

Figure 3. Adoption of Facebook

Thirty-three participants (66\%) had positive views about Facebook, while 1 participant was negative. Almost all participants (96\%) agree that membership to Facebook is easy, but only 33 participants (66\%) stated that use of Facebook is easy.

Forty-one participants (82\%) did not agree that they use Facebook since valued people use it, and again 41 participants (82\%) disagreed with the statement that they started to use it upon recommendation. Twenty-five participants $(50 \%)$ stated that they were using Facebook since group of friends, relatives, and akin etc. also uses it; while 8 participants $(16 \%)$ were neutral to the view.

Twenty-eight participants had positive views on ability to reach information and resources required for using Facebook, while 18 participants (36\%) were neutral about ease of getting support and additional 23 participants (46\%) stated that they could easily get support.

Considering the similarity of Facebook with other sharing and communication environments, 27 participants (54\%) stated similarity, $12(24 \%)$ stated they were neutral and $11(22 \%)$ stated dissimilarity. With regards to access to Facebook at any time at anywhere with Internet access, 41 participants (82\%) stated positive approach.

Thirty-one participants (62\%) stated that they customized Facebook profiles. When rates pertaining to learning and arranging activities via Facebook are examined, it is observed that 25 participants (50\%) had positive attitude, $14(28 \%)$ were negative and 11 participants (22\%) were neutral. 
Thirty-seven participants (74\%) stated that they were acting based on their personal interests and needs. Considering the item about approaches to create groups, $31(62 \%)$ stated negative attitudes, while 19 (38\%) agreed that groups reinforce communication and relations, 20 (40\%) stated the disagreement and 11 participants $(22 \%)$ were neutral.

Participants using Facebook for collaboration with individuals sharing common interests and aims consisted of 16 instructors (32\%). With regard to the same question, 14 (28\%) were neutral, and 20 participants (40\%) disagreed.

With consideration to meeting with others having common field of interest via Facebook, 19 participants (38\%) had positive and 19 participants (38\%) had negative attitude, while others stated that they were neutral.

Fifteen participants (30\%) mentioned that they had good time via applications such as games in Facebook, while 31 participants (62\%) stated that they did not use such applications.

When overall approach to Facebook is considered, it was revealed out that instructors had positive attitudes and they were using the network particularly for communicating and sharing. The use for making announcement to and sharing with friends in the profile list is widespread. It is also used for learning reactions of others to events and messages shared and for forming an opinion. Instructors found participation to social networks easy, learning the use of this environment not difficult, and the software user-friendly. It appears that Facebook provides support for enabling users communicate and share comfortably and easily.

Disagreement of instructors to the view that they joined Facebook upon recommendation or as others are present in this environment indicates that absence in this environment is their preference. They join Facebook since they found it beneficial and they actively use interactivity of the environment. It is easy to login Facebook from anywhere with Internet access. Instructors customize the account such that it reflects the owner of the account and their needs and learning activities are arranged and shared with friends on this environment. A positive approach is also observed considering the view that joining groups would reinforce communication and relations. However, there is a negative attitude towards the use of the site for collaborating with individuals having common field of interest. Games are among attractive applications of the Facebook too. Facebook users are interested in games played in virtual environment such as Farmville, Diner dash etc. and they recommend friends participate to those games. It is revealed out that a substantial part of instructors do not participate to such applications. Instructors use Facebook largely for being informed about developments related to friends in their list, communicating with friends as well as relatives, sharing content, and getting or providing feedback.

\section{Intended Use of Facebook}

The interactivity which always increases due to the improving technology laid the ground for new information and communication environments. Social networks are one of these new communication environments. Individuals communicate, interact, cooperate, and even carry out their learning activities through these networks. People are connected to social networks almost every day and they spend some time there, which increases day by day. Many people from different age groups join social networks for different purposes and the number of users joining the social networks is gradually increasing. As mentioned before, the total number of 
Facebook users in the world is above 500 million. The incredible development of the social networks are mainly due to the ability of sharing of personal lives with different individuals, learning of daily news and events, and exchanging information. All these are happening in social networks with remarkable speed and precision.

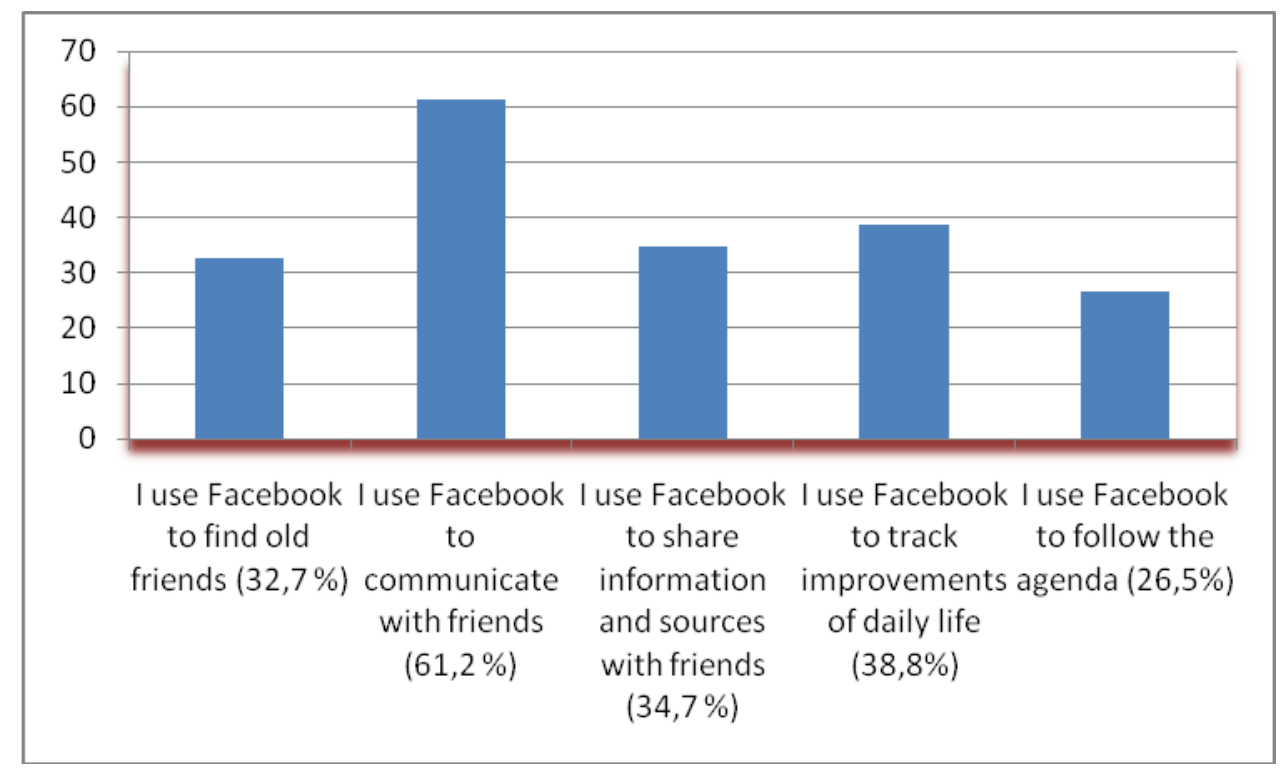

Figure 4. Intended Use of Facebook

One participant chose not to answer the questions in this section, while 2 participants chose not to answer two questions. While 20 participants (40\%) stated that they occasionally use Facebook to find their former friends, 16 (32\%) stated that they often find their former friends via Facebook. These answers appear to be suitable for the opening purposes of Facebook. It is an effective environment in establishing and maintaining social networks. Similarly, the use of Facebook to communicate with friends is high (75\%). Twenty-four participants (49\%), on the contrary, stated that they never use Facebook to make new friends. 12 participants (24\%) stated that they sometimes use Facebook for this reason, only 2 participants (4\%) stated that they often use it.

As far as responses to the question about the use of Facebook to communicate with people who have common hobbies and needs are concerned, 14 participants (28\%) answered "Never", 14 (28\%) answered "Sometimes", and 15 participants (30\%) answered "Sometimes".

Considering the use of Facebook in terms of people's share of different information and sources with each other, 17 participants (34\%) answered "Sometimes", 17 (34\%) answered "Often", 3 (6\%) answered "Always", 6 (12\%) answered "Rarely", and 6 participants (12\%) answered "Never".

The participants stated that they do not share the sources such as assignments and projects on Facebook, 16 participants (32\%) stated that they never use this environment for this purpose. A similar situation is also observed in the use for the support of the academic studies. While 17 participants (34\%) stated that they will never use this environment for supporting the academic studies, $15(30 \%)$ stated that they sometimes use it for this purpose and the number of those who always use it for this purpose is limited to 2 participants (4\%). 
The answers given to the question in terms of following the developments about schoolmates and the changes in their lives highlighted that 17 participants $(35 \%)$ sometimes use this environment for this purpose. It is quite remarkable that 19 participants $(38 \%)$ use Facebook in order to follow the developments in daily life and 13 participants (26\%) use it to follow the current changes.

Instructors use Facebook to find their former friends; however, they do not look positively to making friends with people they do not know or looking for friendships. Finding former friends (primary school, secondary school, high school, university, former workplace, neighborhood, etc.) seems to serve the establishment purposes of Facebook. It is an effective environment in establishing and maintaining social networks. Similarly, Facebook is widely used in order to communicate with friends. The answers given to the questions in the section regarding the adoption of Facebook show that instructors think positively about the involvement in groups and their benefits; however, an unstable attitude was observed in the questions about the groups in the section on adoption. Most of the instructors have some kind of memberships in one or more groups, which can be explained as a reaction against the groups established by those who they do not know about. Instructors are willing to share various information sources; however, it was seen that they are not sure about the share of academic studies such as assignment, articles etc. and the reliability of the shared information and they do not share them. Instructors use Facebook as an instrument to follow the daily developments and keep up with the global and/or national agenda in this environment, which means they adopted Facebook and it has taken its place among the daily life practices.

\section{Use of Facebook for Educational Purposes}

As mentioned earlier, all instructors participating in the present study teach in the Faculty of Communication Sciences. From this perspective, analyses included in this particular section are important. A substantial body of participants, in other words 40 participants (80\%), agrees that Facebook makes contribution to communication between classmates. Instructors have the view that intra-class dialogue may be effectively realized and maintained on this environment and communications of students will not be limited with only course hours. Students with longer communication time will better know each other and they will also conduct better team work.

It should be indicated that in this part of the study, one participant preferred not to answer (4 questions), 2 participants preferred not to answer (6 questions) and 3 participants preferred not to answer one question.

Importance of communication between instructor and student is a non-negligible issue and all the possible tools contributing to this environment should certainly be benefited. Attitude of participants regarding the view that Facebook will contribute to the communication provides support to this idea because 37 participants $(74 \%)$ agree with this view. Only one participant stated that it has no contribution in this area and 3 participants stated disagreement. Although it is considered by participants that it is an effective environment for communication, 21 participants (42\%) were neutral about conducting discussion in the class. Substantial part of participants, namely 21 participants, regard the Facebook suitable for intra-class discussion and 8 participants were neutral on this issue. 


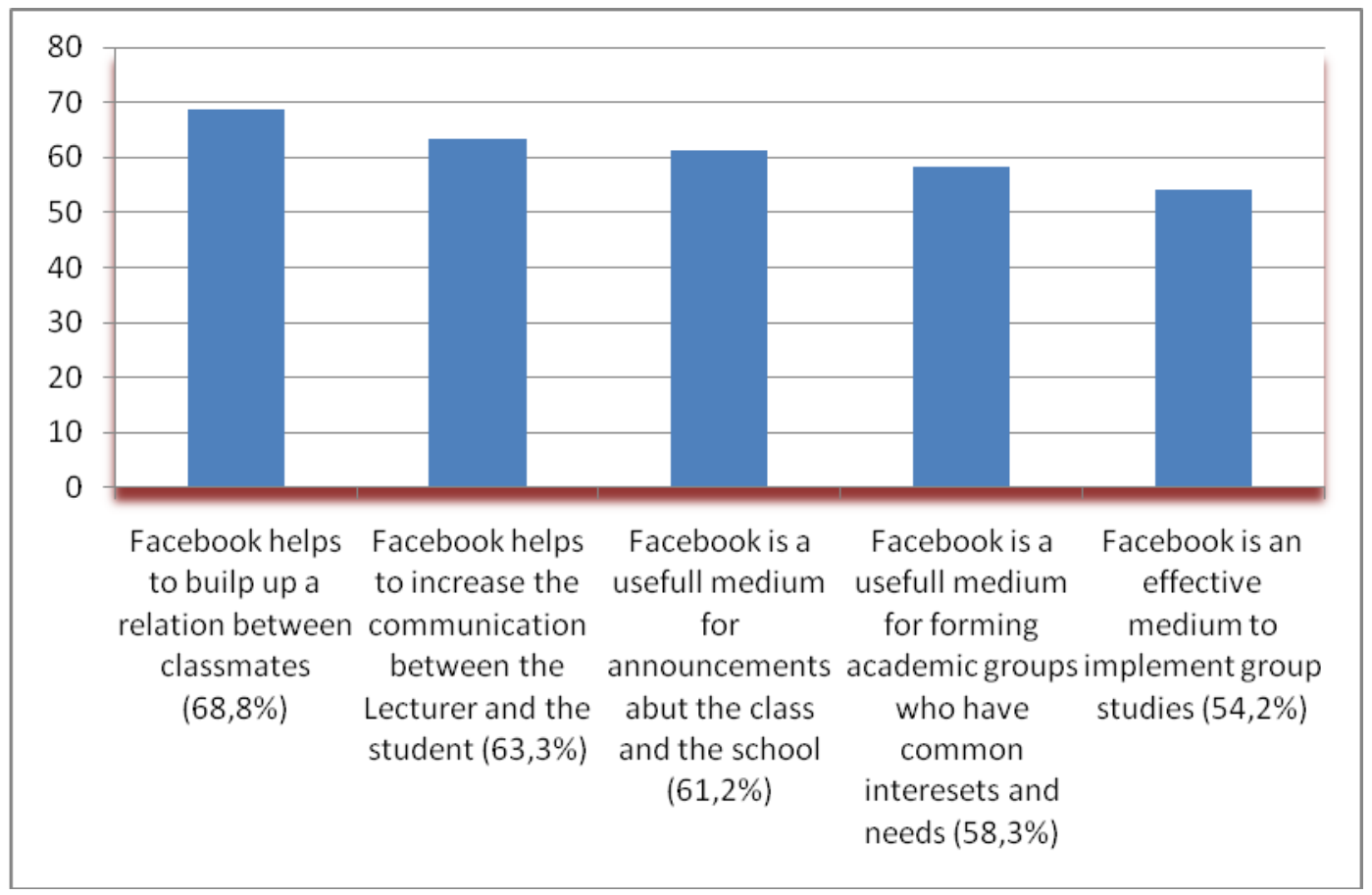

Figure 5. The Use of Facebook for Educational Purposes

Use of Facebook more commonly emerges in the form of announcement and task distribution. The issues with highest agreement were suitability of Facebook for announcement about course, which was agreed by 36 participants (72\%) and announcing home works, which was agreed by 31 participants (62\%).

Instructors have positive attitudes toward creating academic groups with regard to the common field of interest and requirements. Thirty-two participants (64\%) had positive views about Facebook on this issue, while 6 participants (12\%) were negative.

More than half of participants (29 participants) had positive attitudes for conducting group work and sharing information about courses over Facebook. Multiple environment support, benefited during a course or a project, had positive impact on views of instructors and 26 participants (52\%) agree with contribution of video, animation, and auditory support. However, they are still neutral for accepting that it is a safe environment for accessing to education materials. Six participants (12\%) stated strict negative view on this issue, while 7 (14\%) disagreed, 21 (42\%) were neutral and 14 participants $(28 \%)$ had positive views. There is no participant absolutely agreeing this issue.

Only one of 284 courses lectured in the Faculty of Communication Sciences at Anadolu University, where the present study was conducted, is completely offered over Facebook. Instructors generally use this environment as a supplementary environment. Instructors regard Facebook suitable for communicating with students, communication of students with each other, being informed about students and making announcements about courses and sharing content. However, they still have some negative attitudes on completely lecturing courses over Facebook. 
However, it appears that the use of this environment by more instructors for educational purposes is not a distant future because almost all instructors participating in the study somehow use Facebook in their courses; even the instructor with the lowest frequency of using this technology makes announcement about the course by creating a group. It should be noted, on the other hand, that instructors are neutral about efficiency of this environment on intra-class discussions.

Instructors form groups for their large-scaled courses and share information regarding their courses on these group pages. They also supervise or control many group work over Facebook. The multimedia support that can be made use of during the course or the project has affected the instructors' opinion on this matter positively. However, many instructors have remained indecisive on the stage of accepting Facebook as a reliable media for accessing educational materials. Instructors often use Facebook for supporting their courses and for communicating with students. When the data obtained at this section of the study is evaluated as a whole, it appears that instructors do not have an unfavourable attitude of carrying out their courses over Facebook in the near future with a little support.

\section{Conclusion}

Social networks have affected the modern society positively and have changed some of people's habits. Effective use of features and opportunities of social networks supports instructors' empowering of the educational process with active learning, creativity, problemsolving, cooperation, and multifaceted interactions as well as students' using and improving their academic performance, inquiry, and alternative thinking skills.

It develops communication skills, extends participation and social commitment, strengthens peer support, and enables the realization of cooperation-based learning. In addition, social network sites can be used easily and conveniently, they can be integrated into the educational practices successfully and such utilizations are becoming widespread rapidly. Social networks, represented as Facebook in this study, provide the users a communication environment which is not limited with space and time because they are online tools that generate interaction by allowing new opportunities for more information, interest, and data sharing.

Based on the results of this study, social networks are used actively by the instructors in the Faculty of Communication Sciences. The present study shows that instructors in the Faculty of Communication Sciences have adopted Facebook and they are using it intensively. Instructors of the Faculty of Communication Sciences tend toward the use of Facebook for educational purposes as well. A large proportion of the students are able to use social media anytime and anywhere via mobile Internet. Hence, utilization of Facebook to support learning also becomes meaningful and widespread. The instructors have displayed an indecisive approach for the use of Facebook merely for education purpose; they mostly use it as a medium to make contact with students and for sharing information.

Social networks also provide opportunities for the academicians because they are flexible and user friendly, they are used more easily than the other educational management systems. Facebook is used in the delivery of information, reference books, group assignments, and course sessions. Instructors and students can send materials, addresses of web sites, and videos regarding courses on Facebook and presentations, assignments, and other products of the students that can be shared by forming links to Google documents. Facebook can be used 
to share materials (video files, audio files, pictures, spreadsheet, presentation, database, web sites etc.) effectively, follow up current events, news, people or groups, and get involved in discussion environments to support the skills of learning for cooperation, research, discussion, critical thinking, problem solving and so on. A similar result has been obtained in this study as well. Those who have Facebook membership amongst the instructors participating in this study are using these features actively.

Social networking sites are becoming more involved in our daily life day by day. As of today, instructors can neither conduct a course completely through Facebook nor they can ignore this development comfortably. None of the instructors in the current study denies that Facebook is an effective medium; they all agree that educators should benefit from its tools. The younger faculty members use Facebook and similar technologies more in their courses compared to senior faculty members. This might be due to their familiarity and mastery regarding the use of these technologies.

It should be noted that the present study is limited with the findings of a certain academic organization, namely a faculty of communication in Turkey. Both the national and institutional cultures might have affected the results. New studies need to be conducted in other countries and educational settings representing various sensitivities and differences. Studies should also be conducted in so-called high-tech universities offering degrees through virtual technologies. Additionally, future studies may compare experiences of instructors and students regarding the use of social networks in educational practices. Furthermore, new studies may look at how communicational uses of social networks have influenced educational uses. Finally, possible interactions between alternative uses of social networks and individual differences of learners should be investigated.

\section{References}

Akar, E. (2010). Sanal topluluklarin bir turu olarak sosyal ag siteleri: Bir pazarlama iletisimi kanali olarak isleyisi [Social networking sites as a type of virtual communities : Processing as a marketing communication channel]. Eskisehir: Anadolu Universitesi Sosyal Bilimler Dergisi, 10(1), 107-122.

Awl, D. ( 2010). Facebook me! A guide to socializing, sharing, and promoting on Facebook. Berkeley, CA: Peachpit.

Aydogan, F., Akyuz, A. ( 2010). Ikinci medya caginda Internet. Istanbul: Alfa.

Balci, B. (2010). E-ogrenme sistemindeki basari faktorleri. In U. Demiray, G. Yamamoto, M. Kesim. (Eds.). Turkiye'de e-ogrenme: Gelismeler ve uygulamalar (pp. 465-480). [Elearning in Turkey: Developments and applications]. Ankara: Cem Web Ofset.

Bilen, M.( 2002) Plandan uygulamaya ogretim. Ankara: Ani.

Gulbahar, Y., Kalelioglu, F., \& Madran, O. (2010). Sosyal aglarin egitim amacli kullanimi [Educational use of social networks]. XV. Turkiye'de Internet kullanimi konferansi. Istanbul: Istanbul Teknik Universitesi.

http://www.asiamedia.ucla.edu/article.asp?parentid=52164

http://www.ezberim.com/internet-haberleri/167867-Facebook-sitesinin-kurulus-hikayesi

http://www.Facebook.com/press/info.php?statistics. Retrieved on 22 February 2011. 
http://www.nedirbilgi.com

http://www.socialbakers.com/blog/25-countries-with-top-Facebook-penetration-topopulation/ Retrieved on 22 February 2011.

http://www.socialbakers.com/Facebook-statistics/turkey.Retrieved on 22 February 2011.

http://www.theglobeandmail.com/news/technology/personal-tech/Facebook-a-big-hit-withnarcissists-study/article1698694/ Retrieved on 12 March 2011.

http://www.haber3.com

http://www.socialbakers.com

Jones, N., Blackey, H., Fitzgibbon, K., Chew, E. (2010) 'Get out of MySpace!' Computers \& Education, 54, 776-782.

Jordan, T. (1999). Cyberpower. London: Routledge.

Kelsey, T. ( 2010) Social networking spaces: From Facebook to Twitter and everything in between (beginning). New York: Apress.

Mattelart, A. (2004). Bilgi toplumunun tarihi. Istanbul: Iletişim.

Murray, C . (2008). Schools and social networking: Fear or education? Synergy Perspectives: Local, 6(1), 8-12.

Osuagwu, N.G. ( 2009). Facebook addiction: The life \& times of social networking addicts. Philadelphia: Ice Cream Melts Publishing.

Perlman, D. \& Miller, R. (2008). Intimate relationships. New York: McGraw-Hill.

Seguin, A. \& Seguin, C. ( 1995). Window to the world. Vocational Education Journal, 70, 30-33.

Shih, C. ( 2009). The Facebook era: Tapping online social networks to build better products, reach new audiences, and sell more stuff. Ohio: Prentice Hall.

Toprak, A. ( 2009). Toplumsal paylasim agi Facebook. Istanbul: Kalkedon.

Yamamoto, G. T., Demiray, U., \& Kesim, M. (Eds.). (2010). Turkiye'de e-ogrenme: Gelismeler ve uygulamalar [E-learning in Turkey: Developments and applications]. Ankara: Cem Web Ofset.

Correspondence: Filiz Tiryakioglu, Associate Professor, Faculty of Communication Sciences, Anadolu University, Yunus Emre Campus, Eskisehir, Turkey. 